\title{
A Natural Product that Accelerates Hair Growth in Women with Chemotherapy-Induced Alopecia
}

\author{
María Rosario Alonso and Claudia Anesini* \\ Universidad de Buenos Aires, Consejo Nacional de Investigaciones Científicas y Técnicas (CONICET), Instituto de Química y \\ Metabolismo del Fármaco (IQUIMEFA), Facultad de Farmacia y Bioquímica, Junín 956, Piso $3^{\circ}$ (1113), Buenos Aires, Argentina
}

\begin{abstract}
Background: Chemotherapy-induced alopecia (CIA) is an adverse effect with a negative impact on quality of life, particularly in women. A lotion containing Larrea divaricata and Coffea arabica extracts to induce hair growth is commercially available in Argentina. The objective of this work was to evaluate the capacity of the lotion, to accelerate post-chemotherapy hair growth in women.
\end{abstract}

\section{Methods}

Design: A prospective controlled, randomized, double-blind clinical trial was performed.

Clinical Trial Registration No: CEICYT-UAI, protocol no. 0-1026- 26/12/2017.

Setting: Hospital Austral, Buenos Aires, Argentina.

Participants: female patients, with ages ranging from 35 to 75 years, with diagnosis of cancer who had received the last chemotherapy cycle with drugs that cause alopecia four weeks before recruitment.

Measurements: The lotion or placebo were applied once a day and photographs of the lateral, occipital and coronary views were taken to determine the percentage of hair coverage at day $0,30,60$ and 90.

Results: After 30 days the lotion increased $613 \%$ hair growth $(\mathrm{p}<0.05)$ and speed of hair appearance. The time elapsed from the initial visit to the time of appearance of a normal amount hair, was $57 \pm 10$ days for control patients and $39 \pm 5.8$ days for patients treated with lotion. No adverse events were observed.

Conclusion: Results support the use of the lotion as a safe and affordable treatment that can accelerate hair growth in women with CIA.

KEYWORDS: Chemotherapy-induced alopecia; Hair growth; Larrea divaricata; Coffea arabica

ABBREVIATIONS: CIA: Chemotherapy-Induced Alopecia; DP: Dermal Papillae; DPCs: Dermal Papillae Cells; FAGA: Female Androgenetic Alopecia; VEGF: Vascular Endothelial Frowth Factor; CIs: Confidence Intervals; ROS: Reactive Oxygen Species; Px: peroxidase; CAT: catalase; SOD: Superoxide Dismutase; STZ: Streptozotocin

Quick Response Code:

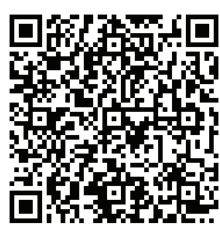

Address for correspondence: Claudia Anesini, PhD, Universidad de Buenos Aires, Consejo Nacional de Investigaciones Científicas y Técnicas (CONICET), Instituto de Química y Metabolismo del Fármaco (IQUIMEFA), Facultad de Farmacia y Bioquímica, Argentina

Received: July 11, $2021 \quad$ Published: July 21, 2021

How to cite this article: María Rosario Alonso and Claudia Anesini. A Natural Product that Accelerates Hair Growth in Women with Chemotherapy-Induced Alopecia. 2021- 3(4) OAJBS. ID.000305. DOI: $10.38125 / \mathrm{OAJBS} .000305$ 


\section{BACKGROUND}

Hair is a body appendage that exerts protective, sensory, thermoregulatory, and sexual attractiveness functions [1]. It is a complex mini organ composed of terminally differentiated dead keratinocytes, the matrix cells which originate keratinocytes, and dermal papillae (DP) containing fibroblasts [2] located in the deepest end of the follicle. Fibroblasts are thought to play essential roles in the induction of new hair follicles and the maintenance of hair growth $[3,4]$. Dermal papillae cells (DPCs) are not only essential for hair follicle development by secreting growth factors, which stimulate the proliferation and differentiation of the follicular epithelium [5,6], but they are also a cell reservoir that can differentiate into a range of cell types of potential therapeutic importance [7]. Hair growth is cyclical, and it is divided into mainly 3 following phases: anagen phase (growth), catagen phase (regression), and telogen phase (resting) [8]. These cyclic changes involve rapid remodeling of both the epithelial and dermal components of hair follicles $[9,10]$.

It is known that the deregulation of the hair growth cycle caused by an imbalance between cell growth and death (by apoptosis) is associated with different types of alopecia, a generic term for hair loss, which results in a decrease in the amount of visible hair. The most common types of alopecia are androgenetic alopecia or common baldness, telogen effluvium, alopecia areata and CIA (Figure 1).

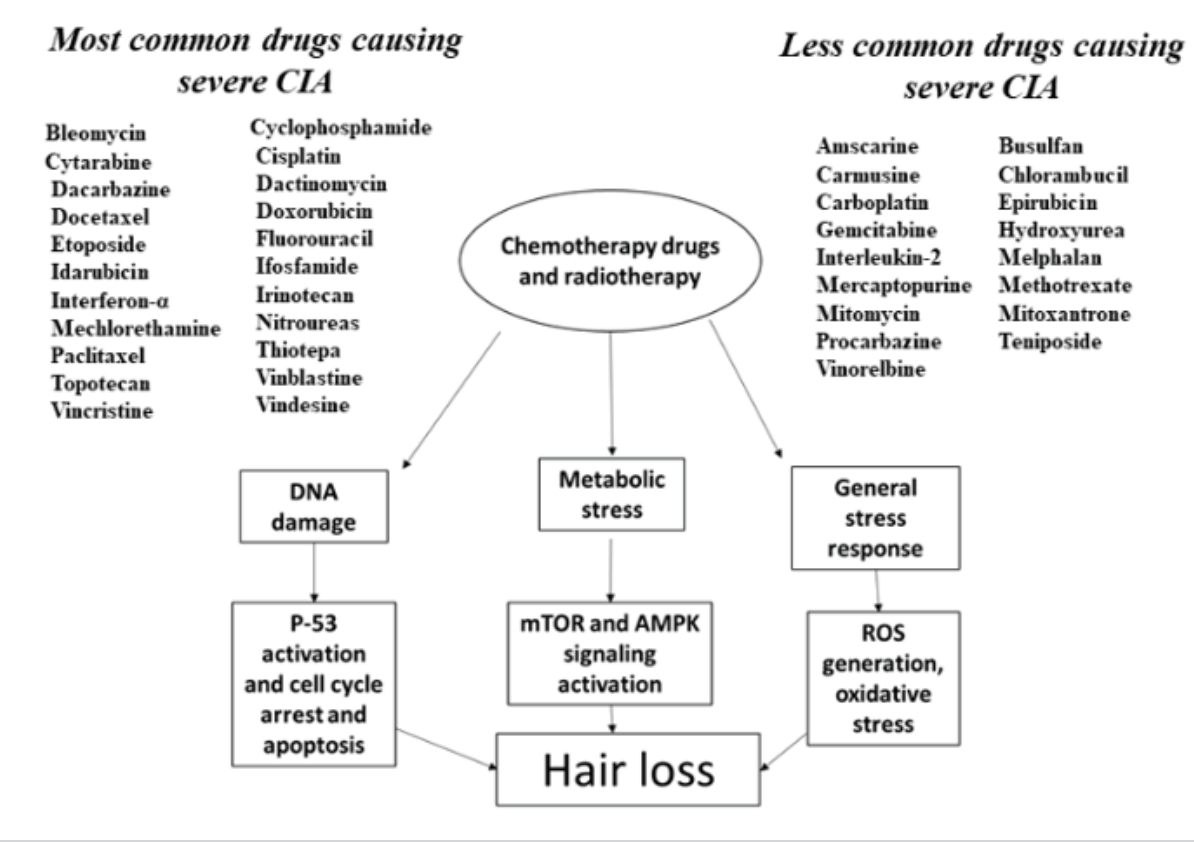

Figure 1: Mechanisms by which chemotherapy and radiotherapy induce CIA and chemotherapy induce alopecia.

CIA is an emotionally distressing condition in humans occurring as a side effect of chemotherapy and/or exposure to X-rays [11]. This type of alopecia occurs in about $65 \%$ of patients receiving cytotoxic drugs [12] and can occur from a few days to weeks after the beginning of chemotherapy, with different shedding patterns depending on the severity of the insult. Chemotherapy drugs can produce either telogen effluvium, associated with mild to moderate damage or anagen effluvium, associated with a more serious damage.

The main targets of anti-cancer drugs are the matrix keratinocytes, which are highly proliferative during the anagen phase, and their pigmentary system. These structures are very sensitive to toxins and drugs, which can cause rapid cell apoptosis $[12,13]$. As a rule, the catagen and telogen phases are not affected because they are mitotically inactive, but when hair is in late anagen phase, characterized by a lower mitotic rate, chemotherapy accelerates the normal transition to the telogen phase $[12,13]$. Considering that up to $90 \%$ of scalp hairs are normally in the anagen phase, it is easy to explain why the scalp is the most frequently affected area. Conversely, the degree of damage to areas of the beard, eyebrows, and eyelashes, as well as axillary and pubic regions will depend on the percentage of hairs in the anagen phase.
CIA reverts in about 3 to 6 months, but in some cases, chemotherapy causes a rare permanent alopecia leading to considerable psychological damage [12-14]. Alopecia negatively influences the body image, sexuality, and self-esteem, as a consequence, up to $8 \%$ of patients refuse chemotherapy when there is risk of hair loss [11]. The prevalence and severity of hair loss are related to the drug category and to the number of drugs administered. The incidence of alopecia has been reported to be about $80 \%$ for antimicrotubule agents, $60 \%-100 \%$ for topoisomerase inhibitors, $>60 \%$ with alkylating agents, and 10 $50 \%$ with antimetabolites [12]. Moreover, novel anticancer drugs such as bortezomib and vismodegib also induce alopecia $(14.7 \%$ incidence), with the quality of hair and rate of regrowth also being affected [15].

Some drugs are related to the development of permanent alopecia such as cyclophosphamide, thiotepa, carboplatin (CTC regimen) and drugs used in the treatment of breast cancer such as taxanes alone, docetaxel or paclitaxel [16,17], or a regime of docetaxel, carboplatin and trastuzumab [18]. A case series report showed the development of severe and permanent alopecia in 20 women treated for breast cancer by a sequential fluorouracil/ epirubicin/cyclophosphamide (FEC) and docetaxel regime [16]. 
Aromatase inhibitors, which decrease estrogen levels, induce frontal and parietal hairlines, diffuse hair loss and miniaturization of follicles in the fronto-temporal area, mimicking a typically female androgenetic alopecia (FAGA) with male pattern [19]. Therefore, and depending on the dose, the time, and the drugs combination, the severity and hair growth may vary among subjects.

Many drugs have been tested to avoid CIA, but none of them have been approved because of their limited and transient effectiveness and adverse effects. Among these is minoxidil, a drug that induces the opening of potassium channels that stimulates keratinocyte proliferation, inhibits collagen synthesis and production; and stimulates the synthesis of vascular endothelial growth factor (VEGF) and prostaglandins. It has been demonstrated that minoxidil prolongs the duration of the anagen phase and enlarges miniaturized follicles [20]. However, this drug may cause pruritus, skin dryness, scaling, local irritation, and dermatitis [2123]. Minoxidil must be applied twice a day on the affected areas for at least 6 months. Another agent proposed to facilitate hair regrowth after chemotherapy is calcitriol (1,25-dihydroxyvitamin $\mathrm{D}_{3}$ ), which has multiple effects on keratinocytes but causes contact dermatitis; therefore, it must be used with caution, particularly when applied topically. Finasteride, a dihydrotestosterone-5- $\alpha$ -reductase inhibitor, causes many adverse effects and cannot be used in women because it is known to cause teratogenic effects in a developing male baby. Besides, it causes irreversible side effects on sexual functionality and induces CNS depression [24].

Considering this information, novel innocuous pharmacological treatments are needed to induce hair growth in chemotherapytreated patients. A combination of extracts obtained from two plant species, i.e., Coffea arabica and Larrea divaricata, elaborated by Garré-Guevara laboratory under the trademark of ECOHAIR $®$, is being successfully used in Argentina for hair recovery in the scalp area in cases of androgenic alopecia and alopecia areata and for eyelashes and eyebrows growth. The effectiveness of the product in scalp alopecia and for eyelashes and eyebrows growth as well the lack of topical adverse effects has been assessed in two clinical trials $[25,26]$. To provide scientific support for its effect in the treatment of CIA, the product was tested in volunteers. The primary objective of this prospective study was to evaluate the capacity of the lotion to accelerate hair growth and to reduce the duration of alopecia in women treated with chemotherapeutic drugs.

\section{MATERIALS AND METHODS}

\section{Study Design}

A prospective controlled, randomized, double-blind clinical trial was performed. This study has been evaluated and authorized by the Ethics Committee of Universidad Abierta Interamericana (UAI), Buenos Aires, Argentina. This study has been carried out in the Hospital Austral, Buenos Aires, Argentina, during September 2018 and December 2019, 2019, by the direction of Dr Marcelo Blanco Villalba who planned the trial performing visits and instrumental evaluation and protocol design.

\section{Subject}

All patients included in the study signed an informed consent. Patients did not receive any kind of financial support to participate in the study.

Inclusion criteria: Female patients, with ages ranging from 35 to 75 years, with diagnosis of cancer who had received the last chemotherapy cycle with drugs that cause alopecia four weeks before recruitment.

Exclusion criteria: Patients with known sensitivity to any of the components of ECOHAIR $囚$. Patients who cannot carry out the application of the lotion by themselves and/or with the help of their family. Patients who have not signed the informed consent. Patients with scarring alopecia. Patients who must be treated with a topical medicine in alopecia. Patients undergoing treatment with vasodilators, vitamins, zinc, phlebotonics or antibiotics. Patients suffering from mental disorders: cognitive developmental delay, cerebral palsy, or mental deficits of any kind.

\section{Procedure}

The objective of this study was to determine the capacity of the lotion to improve and accelerate the hair growth in patients after chemotherapy treatment and to evaluate any adverse events that could arise during the treatment. Patients receiving either the treatment or the placebo were previously randomized. The Table of Random Numbers from the Dawson-Saunders Beth book was used [27]. At all times of the study, the treating physician, the principal investigator, the patient, and the image evaluator were unaware if each patient's lotion corresponded to the treatment or the placebo. The envelopes were placed on guard and opened when all the results of all the patients were analyzed and recorded.

The treatment consisted of ECOHAIR® Spray Lotion (Res MS and AS155 / 98 Leg Elab: 2720. Laboratorios Garré Guevara SRL República Argentina) Grade 2 cosmetic product. The placebo contained only the excipients of the treatment product. In the initial visit, each patient received training on how to apply the lotion. The lotion was applied once a day at night immediately before going to bed by a gentle massage using the fingertips on the entire scalp including areas covered with hair. Patients were evaluated at baseline and during visits scheduled on days 30, 60 and 90.

At the time of inclusion, each patient received a numbered lotion, neither the treating physician nor the external evaluator knew whether it was treatment or placebo. The number of patients was recorded in the recruitment form. The Patient Data Record was completed including the patient's demographic data. Each patient was trained to complete the evolution record daily during the treatment.

\section{The evolution record included:}

a) The level of patient's satisfaction with the intervention performed. The level of satisfaction, defined as the number that derives from the patient evaluation tables, was from 0 to 4 ; with 0 being the best possible patient's perception and 4 being the worst possible patient's perception. Each patient recorded her own assessment of alopecia every three days.

b) The time (days) elapsed from recruitment (start of treatment or control, total alopecia) to the first visual evidence of hair appearance, as assessed visually by the patient.

In all visits, including the initial one, photographs of the lateral, occipital and coronary views were taken. The numbered photographs were analyzed to determine the percentage of hair coverage using the Image JUS National Institutes of Health image processing program. Areas were expressed in square centimeters. Results were expressed in percentage area covered by hair in relation to the total area. Image processing was performed by an investigator who did not know the patients. 


\section{Statistical Analysis}

Comparisons of efficacy and safety were conducted using the placebo group as reference. The statistical analysis was carried out with the Graphpad Prism 8 software. Differences between groups were assessed using $95 \%$ confidence intervals (CIs), and to compare two means, the student's t test was used. Values of $p<0.05$ were considered significant.

\section{RESULTS}

\section{Patient's Clinical-Pathological Characteristics}

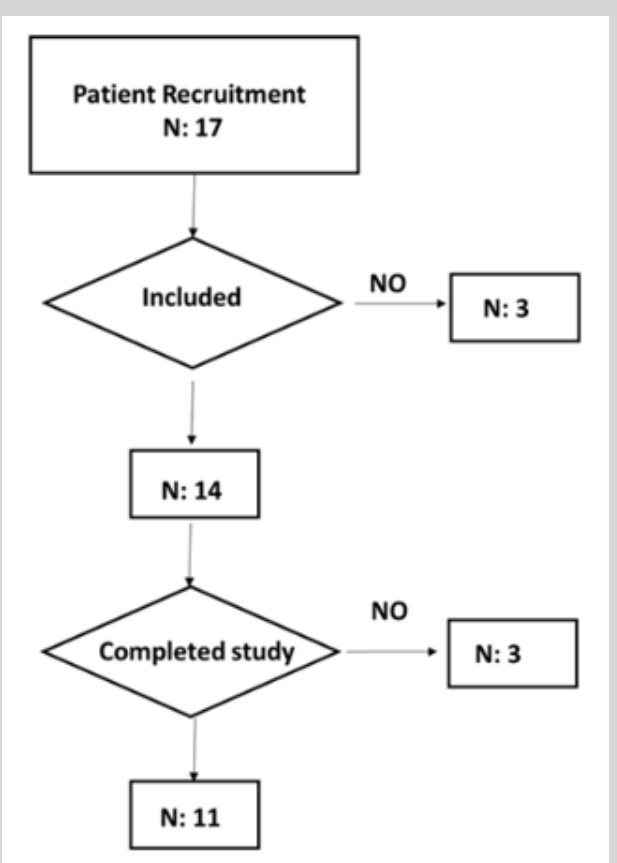

Figure 2: Patient inclusion flowchart.

The patient inclusion flowchart was done in relation to the number of patients recruited and the number of patients who concluded the study.

Table 1: Patient's clinical-pathological characteristics.

\begin{tabular}{|c|c|c|c|}
\hline \multicolumn{4}{|c|}{ Placebo-Treated Group } \\
\hline Age categories & Type of cancer & Chemotherapy Drugs & Hair Covered Area (\%) day 0 \\
\hline 72 & Breast carcinoma & Doxorrubicin + Cyclophosphamide & 0 \\
\hline 40 & Breast carcinoma & Paclitaxel & 0 \\
\hline 56 & Breast carcinoma & Doxorrubicin + Cyclophosphamide & 4.375 \\
\hline 64 & Breast carcinoma & Paclitaxel & 94.587 \\
\hline 68 & Pulmonary carcinoma & Etoposide/Cisplatin & 4.747 \\
\hline $60.0 \pm 1.34$ & & & $20.74 \pm 10$ \\
\hline \multicolumn{4}{|c|}{ Lotion-Treated Group } \\
\hline Age categories & Type of cancer & Chemotherapy drugs & Hair Covered Area (\%) day 0 \\
\hline 65 & Breast carcinoma & Docetaxel & 2.89 \\
\hline 42 & Breast carcinoma & Doxorrubicin + Cyclophosphamide & 60.815 \\
\hline 59 & Breast carcinoma & Doxorrubicin + Cyclophosphamide & 8.654 \\
\hline 60 & Breast carcinoma & Paclitaxel & 0 \\
\hline 64 & Pulmonary carcinoma & Etoposide/Cisplatin & 0 \\
\hline 42 & Breast carcinoma & Paclitaxel & 8.963 \\
\hline $55.3 \pm 4.31$ & & & $13.55 \pm 9.59$ \\
\hline (95\%C.I., $p=0.533$ ) & & & $(95 \%$ C.I., $p=0.725)$ \\
\hline
\end{tabular}


In this study, 17 patients were recruited, 3 patients were excluded from the beginning of the study because they met some exclusion criteria. Of the 14 patients included at the beginning of the study, 3 did not comply with the established visit regime (21\%). A total of 11 patients completed the study (Figure 2). The control and treatment groups comprised 5 and 6 patients, respectively. No statistical differences were found in the mean age and the percentage area covered with hair between groups (95\% CI, p=0.533 and 95\% $\mathrm{CI}, \mathrm{p}=0.725$ respectively). Being able to consider both groups as homogeneous. Table 1 shows the baseline characteristics of both groups as regards age, type of cancer, chemotherapy drugs received for treatment and area with initial hair.

\section{Effect of the Lotion on Hair Growth}

Table 2: Percentage of hair covered area on days 30, 60 and 90.

\begin{tabular}{|c|c|c|c|c|c|}
\hline \multicolumn{6}{|c|}{ Placebo-Treated Group } \\
\hline $\begin{array}{c}\text { Hair Covered } \\
\text { Area (\%) Day } 30\end{array}$ & $\begin{array}{c}\text { Hair Covered } \\
\text { Area (\%) Day } 60\end{array}$ & $\begin{array}{c}\text { Hair Covered } \\
\text { Area }(\%) \text { Day } 90\end{array}$ & $\begin{array}{c}\text { Hair Covered Area } \\
\text { Percentage Difference } \\
\text { Day } 30 \text { - Day } 0\end{array}$ & $\begin{array}{c}\text { Hair Covered Area } \\
\text { Percentage Difference } \\
\text { Day } 60 \text { - Day } 30\end{array}$ & $\begin{array}{c}\text { Hair Covered Area } \\
\text { Percentage Difference } \\
\text { Day } 90 \text { - Day } 60\end{array}$ \\
\hline 29 & 71 & 99.784 & 29 & 42 & 28.784 \\
\hline 78.108 & 97.417 & 99.812 & 78.108 & 19.309 & 2.395 \\
\hline 6.354 & 92.648 & 99 & 1.979 & 86.294 & 6.352 \\
\hline 99.568 & 99.966 & 100 & 4.981 & 0.398 & 0.034 \\
\hline 80.5 & 100 & 100 & 75.753 & 19.5 & 0 \\
\hline $58.710 \pm 17.5$ & $92.210 \pm 5.46$ & $99.720 \pm 0.185$ & $37.964 \pm 16.58$ & $33.500 \pm 14.75$ & $7.513 \pm 5.44$ \\
\hline \multicolumn{6}{|c|}{ Lotion-Treated Group } \\
\hline $\begin{array}{c}\text { Hair Covered } \\
\text { Area (\%) Day } 30\end{array}$ & $\begin{array}{c}\text { Hair Covered } \\
\text { Area }(\%) \text { Day } 60\end{array}$ & $\begin{array}{c}\text { Hair Covered } \\
\text { Area (\%) Day } 90\end{array}$ & $\begin{array}{c}\text { Hair Covered Area } \\
\text { Percentage Difference } \\
\text { Day } 30 \text { - Day } 0\end{array}$ & $\begin{array}{c}\text { Hair Covered Area } \\
\text { Percentage Difference } \\
\text { Day 60 - Day } 30\end{array}$ & $\begin{array}{c}\text { Hair Covered Area } \\
\text { Percentage Difference } \\
\text { Day } 90 \text { - Day } 60\end{array}$ \\
\hline 99.946 & 99.982 & 100 & 97.056 & 0.036 & 0.018 \\
\hline 99.863 & 99.68 & 99.914 & 39.048 & -0.183 & 0.234 \\
\hline 98.592 & 100 & 100 & 89.938 & 1.408 & 0 \\
\hline 95.897 & 99.114 & 100 & 95.897 & 3.217 & 0.886 \\
\hline 95.724 & 100 & 100 & 95.724 & 4.276 & 0 \\
\hline 89.704 & 100 & 100 & 80.741 & 10.296 & 0 \\
\hline \multirow[t]{2}{*}{$96.620 \pm 1.58$} & $99.800 \pm 0.14$ & $99.990 \pm 0.014$ & $83.067 \pm 9.14$ & $3.175 \pm 1.59$ & $0.189 \pm 0.144$ \\
\hline & & & $(95 \%$ C.I., $p=0.034)$ & $(95 \%$ C.I., $p=0.050)$ & (95\% C.I., $p=0.170)$ \\
\hline
\end{tabular}

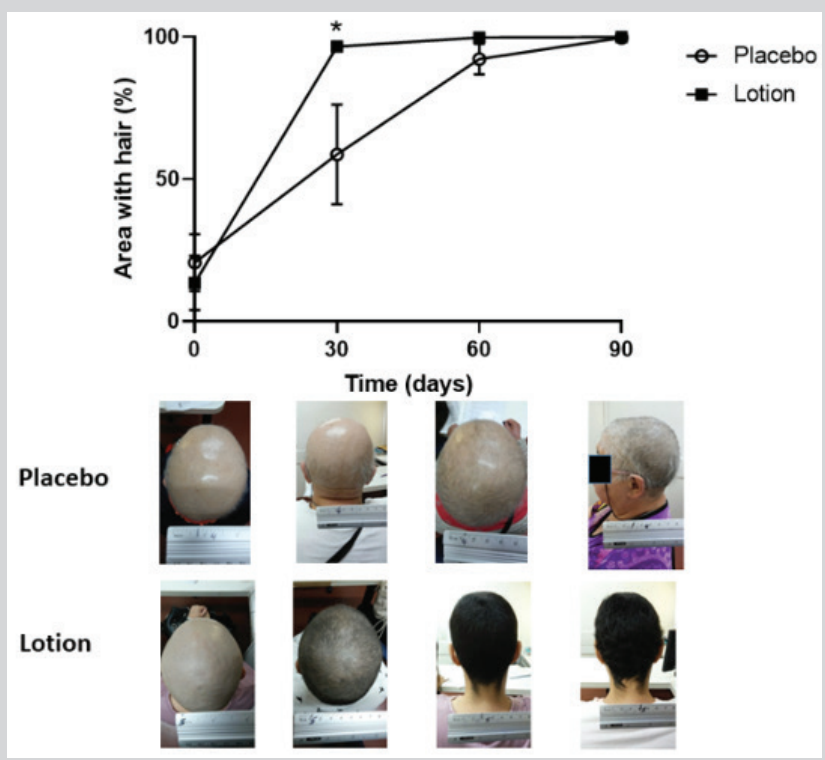

Figure 3: Effect of the lotion on percentage area with hair during the course of treatment.

Results represent mean \pm SEM of 5 patients treated with placebo and of six patients treated with the lotion. $p<$ 0.05 significant differences between placebo and lotion-treated patients (Student's t test). Photographs inserted: representative photographs of one patient treated with placebo and one patient treated with the lotion on days $0,30,60$ and 90 . 
The percentage area covered with hair was determined for placebo-treated patients and in lotion-treated patients on days 30, 60 and 90 days of the treatment (Table 2 and Figure 3). The area covered with hair increased on days 30,60 and 90 days in both placebo- and lotion-treated patients, but after 30 days of treatment with the lotion, the increase $(613 \%)$ was significant $(p<0.05)$ and higher than that obtained with placebo (183\%, see also Figure 3, photographs inserted). No significant differences were observed between placebo- and lotion-treated patients on days 60 and 90. No statistical differences between the difference of the percentage area with hair on days $30-60$ and days 60-90 in placebo- and lotion-treated patients was observed $(95 \% \mathrm{CI}, p=0.050$ and $95 \%$ CI, $p=0.170$, respectively).

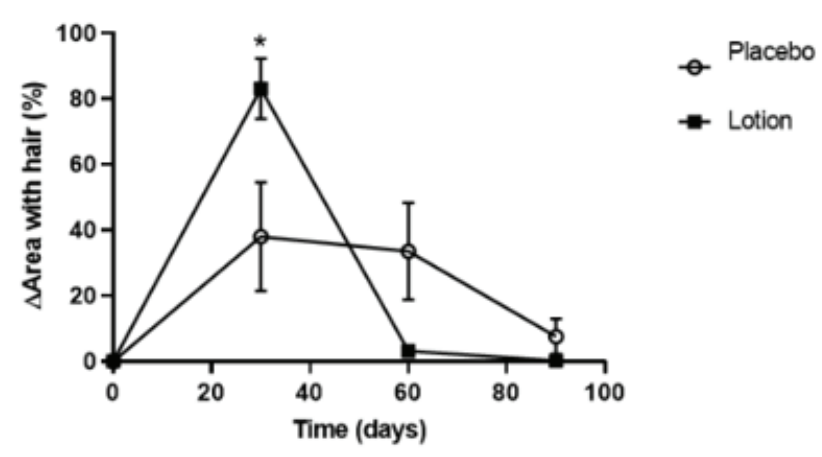

\begin{tabular}{|c|c|c|c|}
\hline Time (days) & $\begin{array}{c}30 \\
\text { Speed of hair }\end{array}$ & $\begin{array}{l}60 \\
\text { rowth }\end{array}$ & $\begin{array}{l}90 \\
\text { tarea of hair/30 days) }\end{array}$ \\
\hline Placebo & 1.26 & 1.11 & 0.25 \\
\hline Lotion & 11.16 & 0.10 & 0.0063 \\
\hline
\end{tabular}

Figure 4: Effect of the lotion on the speed of hair growth

Results represent mean \pm SEM of 5 patients treated with placebo and of six patients treated with the lotion. $p<0.05$ significant differences between placebo and lotion-treated patients (Student's t test). Table inserted: Speed of hair growth over time.

Table 3: Patient evolution record.

\begin{tabular}{|c|c|c|c|}
\hline \multicolumn{4}{|c|}{ Patient Satisfaction Level (Placebo-Treated Group) } \\
\hline $\begin{array}{c}\text { Score of Initial Perception of } \\
\text { Amount of Hair }\end{array}$ & $\begin{array}{c}\text { Number of Days from } \\
\text { Initial Visit to Normal Hair } \\
\text { Perception }\end{array}$ & $\begin{array}{l}\text { Number of Days from Initial } \\
\text { Visit to Visualization of First } \\
\text { Hair Growth }\end{array}$ & $\begin{array}{c}\text { Events/ Adverse Effects// } \\
\text { Adverse Events }\end{array}$ \\
\hline 4 & 87 & 6 & NO \\
\hline 4 & 57 & 4 & NO \\
\hline 3 & 69 & $\mathrm{~N} / \mathrm{A}$ & NO \\
\hline 1 & 24 & $\mathrm{~N} / \mathrm{A}$ & NO \\
\hline 0 & 48 & $\mathrm{~N} / \mathrm{A}$ & NO \\
\hline \multicolumn{4}{|c|}{ Patient Satisfaction Level (Lotion-Treated Group) } \\
\hline $\begin{array}{c}\text { Score of Initial Perception of } \\
\text { Amount of Hair }\end{array}$ & $\begin{array}{c}\text { Number of Days from } \\
\text { Initial Visit to Normal Hair } \\
\text { Perception }\end{array}$ & $\begin{array}{l}\text { Number of Days from Initial } \\
\text { Visit to Visualization of First } \\
\text { Hair Growth }\end{array}$ & $\begin{array}{l}\text { Events/ Adverse Effects// } \\
\text { Adverse Events }\end{array}$ \\
\hline 4 & 24 & $\mathrm{~N} / \mathrm{A}$ & NO \\
\hline 2 & 24 & $\mathrm{~N} / \mathrm{A}$ & NO \\
\hline 3 & 36 & N/A & NO \\
\hline 4 & 57 & 3 & NO \\
\hline 4 & 54 & 2 & NO \\
\hline 3 & 39 & $\mathrm{~N} / \mathrm{A}$ & NO \\
\hline \multicolumn{4}{|c|}{ Self-appraisal: 0: Normal 1: Quasi-normal 2: Acceptable } \\
\hline & 3: Significant hair & ss 4: Total hair Loss & \\
\hline
\end{tabular}


The speed of hair growth is shown in Figure 4 \& Table 3 inserted. The $\Delta_{\text {area }}$ and the speed of hair growth reached a maximum on day 30 and then decreased over time in both placebo- and lotion-treated patients. The maximum reached with the lotion treatment was higher than that observed with placebo. All patients who completed the study completed the evolution record (Table 3). As for the patient's own assessment of alopecia at the start of treatment, it can be seen that in the control group, 2 patients reported the absence of hair at the beginning of the study, one reported to have a limited amount of hair, 1 reported to have a normal amount of hair and another patient reported an almost normal quantity of hair. In the treatment group, 3 patients reported the absence of hair at the beginning of the study, 2 patients reported a great scarcity of hair and 1 patient reported to have an acceptable amount of hair.

The time elapsed from the initial visit to the time of appearance of a normal amount hair, as assessed by the patients, was $57 \pm 10$ days for control patients and $39 \pm 5.8$ days for patients treated with lotion. In the case of patients who did not present any hair at the beginning of the treatment, the time elapsed from the initial visit to the first visualization of hair ranged from between 4 to 6 days for control patients and from 2 to 3 days for lotion-treated patients. No adverse events were reported in this study (Table 3).

\section{DISCUSSION}

This work demonstrates that the lotion elaborated with the extracts of Larrea divaricata and Coffeea arabica was capable of accelerating hair growth in patients with different grades of alopecia induced by chemotherapy.

As soon as hair begun to grow on day 30 in both placebo- and lotion-treated patients, those treated with the lotion presented the head completely covered by thick and strong hair, as opposed to those treated with placebo. Moreover, the lotion induced an increase of hair growth that was 3.34 times higher than that observed with placebo. The growth speed was also higher in patients treated with the lotion (8.87 times). The lotion allowed a complete hair recovery within 1 month after chemotherapy, the speed of hair growth decreased significantly after 2 or three months after cancer treatment, in contrast with placebo, in which by that time, areas without hair could still be observed. As well the difference of area covered with hair between day 30 and 60 in placebo- treated patients did not differ significantly from lotion-treated patients, this difference was greater in placebo, showing that hair begun to growth at day 60 in these patients. Meanwhile, the great growth with lotion was seen at day 30 , because of this, the difference between day 60 and 30 was lower that than observed with placebo.

It is known that CIA is a reversible process in which complete hair regrowth generally occurs 3-6 months after the end of treatment. However, in most cases, the newly grown hair is either grey or differs in color, which represents an alteration of the pigmentation process. Moreover, newly grown hair typically exhibits some changes in structure and texture, e.g., increase of coarseness, slow speed of growth, and reduced density $[28,29]$. Although permanent alopecia has been reported, it rarely occurs [30].

The capacity of these extracts to stimulate hair growth has previously been demonstrated in mice, in which the anagen phase of the hair cycle is promoted [31]. The lotion also increased hair volume, thickness, and growth, and improved its appearance. The lotion also decreased hair loss in patients with non-cicatricial alopecia and no adverse local reactions were observed upon treatment with the product [25].

In view of the knowledge of the image itself, the evaluation of the amount of hair that the patient makes was important. In this sense, the self-evaluation of the patients themselves was consistent with the results found, it was found that the "normality (value 0 )" visualized by the patient corresponds to more than $97 \%$ of the area covered with hair. The visualization by the patient as a "Significant Hair Loss (value 3)" was related to values of around $8 \%$ of the surface covered with hair.

The patients in the treatment group considered that they recovered their normal amount of hair in fewer days than the patients who received placebo. Four patients began the treatment with their head completely without hair, two belonged to the control group and two to the treatment group, being in all cases his self-perception "Total Lack of Hair (value 4)". The evaluation of these cases is interesting. The patients who received the treatment with the lotion visualized the appearance of hair earlier than those who received the placebo, in addition to 30 days of treatment and the area covered with hair was greater than $95 \%$ but only on day 57 did they consider that the amount of hair was normal. The patient's self-evaluation of his alopecia is a tool that it must be considered for its use in future research. It was very easy to apply, it gives us a numerical result and expresses the real feeling of the patient regarding his image.

The basic principle of chemotherapy is to impair the mitotic and metabolic capacity of cancer cells, but this process also affects normal cells with a high proliferation rate such as follicle cells. The rapid hair growth as well as the high blood flow rate around the hair bulb facilitates the local accumulation of drugs; and this is a key predisposing factor for rapid development of extensive alopecia [30]. The degree of CIA depends on the type of chemotherapy, dosage regime and route of administration. Almost all chemotherapy agents cause alopecia but with varying degrees of severity and frequency [32]. The most severe alopecia is induced by cisplatin, doxorubicin, cyclophosphamide, paclitaxel and etoposide, the drugs used for the treatment of patients participating in the present work. It is noteworthy that the combinations of two or more chemotherapeutic agents causes a higher incidence and more severe CIA, as occurs with the combination of cyclophosphamide and doxorubicin.

It is known that reactive oxygen species (ROS) can modulate the anagen/catagen phase balance by inducing damage to DNA, proteins and lipids leading to a cell-cycle arrest, cellular senescence, and even cell death of the follicle by apoptosis, thus beginning the catagen phase [33]. Many chemotherapeutic agents induce oxidative stress through multiple mechanisms, i.e., activation of the NADPH oxidase system and the mitochondrial respiratory. Agents that induce a high level of ROS include anthracyclines (e.g., doxorubicin), alkylating agents (e.g., cyclophosphamide), platinum coordination complexes (e.g., cisplatin) and epipodophyllotoxins (e.g., etoposide) [34]. The oxidative stress-induced apoptosis seems to be the most important mechanism of cell death leading to hair loss. Cisplatin has been demonstrated to cause hair loss by inducing oxidative stress and apoptotic effects on DPCs through a decrease of the Bcl-2/Bax ratio [35].

Although the mechanism of action of the lotion was not studied in this work, it can be hypothesized that the extracts could modulate 
the generation of oxidative stress produced by chemotherapy drugs, and cell proliferation and apoptosis, thus inducing hair growth. In this sense, it has been demonstrated that the extract of $L$. divaricata exerts antioxidant activity through peroxidase (Px)-like, catalase (CAT)-like, and superoxide dismutase (SOD)-like as well as free radical scavenging activities [36]. Furthermore, the extract stimulates the secretion of Px in the submandibular glands of normal rats and modulates the level of antioxidant enzymes in the salivary glands of normal and streptozotocin (STZ)-induced diabetic rats [37-39]. The extract also has anti-tumor, immunomodulatory, and anti-inflammatory properties [40-44]. These effects could be important to modulate oxidative stress and inflammation induced by ROS. Furthermore, coffee contains several antioxidant compounds [45] and it is known to exert antibacterial effects [46]. Taken together, these effects could provide a partial explanation for the effect of the extracts on human hair growth.

It is noteworthy that CIA is a very frequent and disturbing adverse effect, mainly for women. This condition has an enormous psychological and social impact on patients, such as stigmatization, constant confrontation with the illness and possible mortality, vulnerability, shame; loss of privacy and punishment, among others $[47,48]$ It has been demonstrated that women and children are the ones most psychologically affected by CIA, to the point that many women decide to reject chemotherapy for fear of developing CIA [49,50]. CIA also results in the reduction of social activities since hair plays, at least in part, a role in social and sexual communications [30]. Additionally, these negative impacts of CIA may contribute to cancer progression because patients become stressed and depressed, which affects the immune function leading to poor therapeutic outcomes [51,52].

Significant progress has been made in the pathobiology and molecular mechanisms of CIA during the past decade, and several physical and pharmacological approaches to treat CIA have been attempted. Among the treatments of CIA, the use of scalp cooling devices during chemotherapy treatment improves the patient's perception of hair retention but does not completely prevent hair loss, particularly if chemotherapeutic drugs are combined [53]. Moreover, the cooling method is expensive and produces adverse effects such as headache, scalp pain, cold intolerance, nausea, and lightheadedness [54]. Furthermore, it is not clear whether there is a correlation between the use of a scalp cooling systems and the increased risk of skin metastases since these systems block the effect of chemotherapy in tumor cells of the skin of the scalp [55]. Scalp cooling is contraindicated in patients with extensive hematologic malignancies, cold agglutinin disease, cryoglobulinemia, cryofibrinogenemia, and sensitivity to cold [56]. Minoxidil, which is used to improve hair growth in postchemotherapy management, causes many adverse effects on the skin [21]. Moreover, the topical application of calcitriol produces contact dermatitis; and is not efficacious in patients under treatment with anthracyclines and cyclophosphamide [57]. The topical administration of the prostaglandin analog dimatoprost was approved by FDA to promote eyelashes growth, but induces local effects such as dermatitis and systemic adverse effects such as headache, infections, hypersensitivity reactions and hepatic alterations; and it cannot be used during pregnancy because it has been classified as drug of the C category by the FDA [58]

It is noteworthy that no adverse events were reported with the lotion employed in this work.

It was very difficult to recruit patients considering what alopecia represents for the patient, fundamentally to her selfperception and the decrease in self-esteem. Even though the number of participants might be considered low, it is important to note that many people in Argentina is using, successfully, the lotion in different grade alopecia which in sum with the results obtained in this prospective, randomized, double-blind, placebo-controlled study are promising for the efficacious and safe use of the lotion in patients with CIA.

\section{CONCLUSION}

The use of jarilla extract lotion (Larrea divaricata) and decaffeinated coffee (Coffea arabica) can be considered a safe and affordable treatment to accelerate hair growth in women with CIA over a short time.

\section{ACKNOWLEDGEMENT}

The authors thank Laboratory Garré-Guevara S.R.L., Argentina for the financial support of this study.

\section{FUNDING}

This work was supported by Laboratory Garré-Guevara S.R.L and partially by PIP 00067CO from CONICET, UBACYT 20020130100686BA from Buenos Aires University.

\section{AUTHOR CONTRIBUTION}

CA: Was involved in conception of the study, analysis, and interpretation of data. Moreover, contributed towards data analysis, drafting, and critically revising the manuscript and agree to be accountable for all aspect of the work.

MRA: Was involved in extract preparation and quality control of products and analysis and interpretation of data.

The authors approved the final version for submission.

\section{ETHICS DECLARATIONS}

\section{Ethical Approval and Consent to Participate}

This study was conducted in accordance with the ethical standards of the institutional and national research committees and with the 1964 Declaration of Helsinki and its later amendments or comparable ethical standards.

The study protocol and informed consent were reviewed and approved by an institutional review board (Comité de Etica para la Investigation Científica y Tecnológica de la Universidad Abierta Interamericana, CEICYT-UAI, protocol no. 0-1026- 26/12/2017). Informed consent was obtained from all participants included in the study.

\section{CONSENT FOR PUBLICATION}

All authors have read and approved the submission of the manuscript to be published in the Journal. The manuscript has not been sent for publication to another journal.

\section{AVAILABILITY OF DATA AND MATERIALS}

All data are contained and described within the manuscript. The datasets used and/or analyzed during the current study available from the corresponding author on reasonable request.

\section{REFERENCES}

1. Ebling FJ (1987) The biology of hair. Dermatol Clin 5: 467-481. 
2. Schneider MR, Schmidt-Ullrich R, Paus R (2009) The hair follicle as a dynamic miniorgan. Curr Biol 19: R132-R142.

3. Oliver RF (1970) The induction of hair follicle formation in the adult hooded rat by vibrissae dermal papillae. J Embryol Exp Morphol 23: 219-236.

4. Jahoda CA, Reynolds AJ (1992) Induction of follicle formation and hair growth by vibrissa dermal papillae implanted into rat ear wounds: Vibrissae-type fibers are specified. Development 115: 1103-1109.

5. Stenn KS, Paus R (2001) Controls of hair follicle cycling. Physiol Rev 81: 449-494.

6. Filsell, W, Little JC, Stones AJ, Granger SP, Bayley SA (1994) Transfection of rat dermal papilla cells with a gene encoding a temperaturesensitive polyomavirus large $\mathrm{T}$ antigen generates cell lines retaining a differentiated phenotype. J Cell Sci 107: 1761-1772.

7. Biernaskie J, Paris M, Morozova O, Matthew F, Marco M, et al. (2009) SKPs derive from hair follicle precursors and exhibit properties of adult dermal stem cells. Cell Stem Cell 5: 610-623.

8. Tiede S, Kloepper JE, Whiting DA, Paus R (2007) The 'follicular trochanter': an epithelial compartment of the human hair follicle bulge region in need of further characterization. Br J Dermatol 157(5): 10131016.

9. Stenn KS, Combates NJ, Eilertsen KJ, Gordon JS, Pardinas JR, et al. (1996) Hair follicle growth controls. Dermatol Clin 14: 543-558.

10. Paus R, Cotsareli G (1999) The biology of hair follicles. N Engl J Med 341: 491-497.

11. Balagula Y, Rosen ST, Lacouture ME (2011) The emergence of supportive oncodermatology: the study of dermatologic adverse events to cancer therapies. J Am Acad Dermatol 65(3): 624-635.

12. Trüeb RM (2010) Chemotherapy-induced hair loss. Skin Ther Lett 15(7): 5-7.

13. Paus R, Haslam IS, Sharov AA, Vladimir AB (2013) Pathobiology of chemotherapy-induced hair loss. Lancet Oncol 14(2): e50-e59.

14. Miteva M, Misciali C, Fanti PA, Vincenzi, C, Romanelli, P, et al. (2011) Permanent alopecia after systemic chemotherapy: a clinicopathological study of 10 cases. Am J Dermatopathol 33(4): 345-350.

15. Belum VR, Marulanda K, Ensslin C, Gorcey L, Parikh T, et al. (2015) Alopecia in patients treated with molecularly targeted anticancer therapies. Ann Oncol 26(12): 2496-502.

16. Kluger N, Jacot W, Frouin E (2012) Permanent scalp alopecia related to breast cancer chemotherapy by sequential fluorouracil/epirubicin/ cyclophosphamide (FEC) and docetaxel: a prospective study of 20 patients. Ann Oncol 23(11): 2879-2884.

17. Prevezas C, Matard B, Pinquier L (2009) Irreversible and severe alopecia following docetaxel or paclitaxel cytotoxic therapy for breast cancer. $\mathrm{Br}$ J Dermatol 160: 883-885.

18. Nangia J, Wang T, Osborne C (2017) Effect of a scalp cooling device on alopecia in women undergoing chemotherapy for breast cancer: The SCALP Randomized Clinical Trial. JAMA 317: 596-605.

19. Rossi A, Iorio A, Scali E (2013) Aromatase inhibitors induce 'male pattern hair loss' in women? Ann Oncol 24(6): 1710-1711.

20. Messenger AG, Rundegren J (2004) Minoxidil: mechanisms of action on hair growth. Br J Dermatol 150: 186-194.

21. Price VH (1999) Treatment of hair loss. N Engl J Med 341: 964-973.

22. DeVillez RL (1990) The therapeutic use of topical minoxidil. Dermatol Clin 8(2): 367-375

23. Rodriguez R, Machiavelli M, Leone B (1994) Minoxidil (Mx) as a prophylaxis of doxorubicin-induced alopecia. Ann Oncol 5(8): 769-770.

24. Rahimi-Ardabili B, Pourandarjani R, Habibollahi P (2006) Finasteride induced depression: a prospective study. BMC Clin Pharmacol 6: 7-12.

25. Alonso MR, Anesini C (2017) Clinical evidence of increase in hair growth and decrease in hair loss without adverse reactions promoted by the commercial lotion ECOHAIR®. Skin Pharmacol Physiol 30: 46-54.

26. Alonso MR, Perez Damonte S, Anesini C (2019) Jarilla-Coffea extract, a natural cosmetic product that improves eyelashes and eyebrows growth in women. Clin Cosmet Investig Dermatol 12: 47-55.

27. Dawson-Saunders B, Trapp R (2004) Table of random numbers. Basic and clinical biostatistics. $4^{\text {th }}$ edn. Lange Medical Books/McGrawHill, New York, USA.

28. Wang J, Lu Z, Au JLS (2006) Protection against chemotherapy-induced alopecia. Pharm Res 23(11): 2505-2514.

29. Trueb RM (2009) Chemotherapy-induced alopecia. Semin Cutan Med Surg 28(1): 11-14.

30. Batchelor D (2001) Hair and cancer chemotherapy: consequences and nursing care-a literature study. Eur J Cancer Care 10(3): 147-163.

31. Davicino R, Alonso R, Anesini C (2010) Activity of a combination of decaffeinated coffee and Larrea divaricata Cav. Aqueous extract on hair growth. Boletín de Patentes 44: P 090101704.

32. Apisanthanarax N, Duvic M (2003) Dermatologic complications of cancer chemotherapy, In: Bast RC, Kufe DW, Pollock RE, Weichsellbaum RR, Holland JF, Frei E Decker (2003) Hamilton, London, 5: 2271-2278.

33. Hogg N (1998) Free radicals in disease. Semin Reprod Endocrinol 16: 241-248.

34. Conklin KA (2004) Chemotherapy-associated oxidative stress: impact on chemotherapeutic effectiveness. Integr Cancer Ther 3(4): 294-300.

35. Luanpitpong S, Nimmannit U, Chanvorachote P (2011) Hydroxyl radical mediates cisplatin-induced apoptosis in human hair follicle dermal papilla cells and keratinocytes through Bcl-2- dependent mechanism. Apoptosis 16: 769-782.

36. Turner S, Zettler G, Barreiro Arcos ML (2011) Effect of streptozotocin on reactive oxygen species and antioxidant enzymes`s secretion in rat submandibulary glands: A direct and an indirect relationship between enzyme activation and expression. Eur J Pharmacol 659: 281-288.

37. Anesini C, Turner S, Borda E (2004) Effect of Larrea divaricata Cav. extract and nordihydroguaiaretic acid upon peroxidase secretion in rat submandibulary glands. Pharmacol Res 49(5): 441-448.

38. Peralta I, Martino R, Zettler G (2013) Modulator activity of an aqueous extract from $\mathrm{l}$. divaricata cav. on basal oxidative and anti-oxidative parameters of normal rat submandibulary glands. Int J Indig Med Plants. 46: 1363-1369.

39. Peralta I, Marrassini C, Arcos MLB (2019) Larrea divaricata Cav. aqueous extract and nordihydroguariaretic acid modulate oxidative stress in submandibular glands of diabetic rats: A buccal protective in diabetes. BMC Complement Altern Med 19(1): 227.

40. Anesini C, Genaro A, Cremaschi G (1996) Immunomodulatory Action of Larrea divaricata Cav. Fitoterapia 67: 329-333.

41. Davicino R, Manuele MG, Turner S (2010) Antiproliferative activity of Larrea divaricata Cav. on lymphoma cell cine: Participation of Hydrogen Peroxide in its action. Cancer Invest 28: 13-22.

42. Martino R, Barreiro Arcos M (2016) Polyphenol rich fraction from Larrea divaricata and its main flavonoid quercetin-3-methyl ether induce apoptosis in lymphoma cells through nitrosative stress. Phytother Res 30(7): 1128-1136.

43. Davicino R, Peralta I, Martino R (2015) Preventive antiinflammatory activity of an aqueous extract of Larrea divaricata Cav. and digestive and hematological toxicity. Int J Pharm Sci Res 6(7): 3515-3523.

44. Martino R, Canale F, Sülsen V (2014) A fraction containing kaempferol3,4'-dimethylether from Larrea divaricata Cav. induces macrophages activation on Candida albicans infected mice. Phytother Res 28(6): $917-$ 924.

45. Ramalakshmi K, Rahath Kubra I, Jagan Mohan Rao L (2008) Antioxidant potential of low-grade coffee beans. Food Res Int 41: 96-103. 
46. Almeida AA, Farah A, Silva DA (2006) Antibacterial activity of coffee extracts and selected coffee chemical compounds against enterobacteria. Agric Food Chem 54: 8738-8743.

47. Freedman TG (1994) Social and cultural dimensions of hair loss in women treated for breast cancer. Cancer Nurs 17(4): 334-341.

48. Pozo-Kaderman C, Kaderman RA, Toonkel R (1999) The psychological aspects of breast cancer. Nursing Practitioner Forum 10(3): 165-174.

49. Munstedt K, Manthey N, Sachsse S (1997) Changes in self-concept and body image during alopecia induced cancer chemotherapy. Support Care Cancer 5(2): 139-143.

50. McGravey EL, Baum LD, Pinkerton RC (2001) Psychological sequelae and alopecia among women with cancer. Cancer Pract 9(6): 283-289.

51. Spiegel D, Giese-Davis J (2003) Depression and cancer: mechanisms and disease progression. Biol Psychiatry 54(3): 269-282.

52. O'Leary A (1990) Stress, emotion, and human immune function. Psychol Bull 108(3): 363-382.
53. Wheelock JB, Myers MB, Krebs HB (1984) Ineffectiveness of scalp hypothermia in the prevention of alopecia in patients treated with doxorubicin and cisplatin combinations. Cancer Treat Rep 69(4): 373375 .

54. Betticher DC, Delmore G, Breitenstein U (2013) Efficacy and tolerability of two scalp cooling systems for the prevention of alopecia associated with docetaxel treatment. Support Care Cancer 21(9): 2565-2573.

55. Breed WPM, van den Hurk CJG, Peerbooms M (2011) Presentation, impact and prevention of chemotherapy-induced hair loss: scalp cooling potentials and limitations. Expert Rev Dermatol 6(1): 109-125.

56. Komen MM, Smorenburg CH, van den Hurk CJ (2013) Factors influencing the effectiveness of scalp cooling in the prevention of chemotherapyinduced alopecia. Oncologist 18(7): 885-891.

57. Hidalgo M, Rinaldi D, Medina G (1999) A phase I trial of topical topitriol (calcitriol, 1,25-dihydroxyvitamin D3) to prevent chemotherapyinduced alopecia. Anticancer Drugs 10(4): 393-395.

58. Abhijeet KJ, Rashmi S, Uday KRKP (2018) Bimatoprost in Dermatology. Indian Dermatol Online J 9(3): 224-228. 